\title{
FACETAS DO DOCENTE UNIVERSITÁRIO: CONHECIMENTO DIDÁTICO OU CONHECIMENTO PRÁTICO
}

\author{
Wagna Silva Souza ${ }^{1}$
}

\section{RESUMO}

O presente estudo vem mostrar que o docente universitário é alguém que possui conhecimentos de diversas áreas, sejam elas de cunho prático ou didático. No entanto, observa-se na literatura atual que tais conhecimentos devem estar entrelaçados, pois não se pode apenas ter o conhecimento prático sem o didático para oportunizar conhecimento. Com base nessa premissa, o presente estudo tem como objetivo apresentar a importância desses conhecimentos andarem lado a lado nas salas de aula, nas universidades com foco numa aprendizagem significativa que ultrapasse a mera transmissão de conhecimento. Para a realização desse estudo foi feita uma pesquisa de cunho bibliográfico, focando renomados teóricos da área e sintetizando suas principais ideias. Sendo assim, esse estudo traz importantes contribuições para os educadores que buscam melhorar cada dia mais sua prática pedagógica.

Palavras-Chave: Docente, universitário, Conhecimento, Sala de aula.

\begin{abstract}
The present study shows that the university teacher is someone who has knowledge in several areas, whether practical or didactic. However, it is observed in the current literature that such knowledge must be intertwined, as it is not possible to just have practical knowledge without didactics to provide knowledge. Based on this premise, the present study aims to present the importance of this knowledge walking side by side in classrooms, in universities with a focus on meaningful learning that goes beyond the mere transmission of knowledge. To carry out this study, a bibliographic research was carried out, focusing on renowned

\footnotetext{
1 Bacharel em Ciências Econômica pela União de Escolas de Ensino Superior Capixaba - UNESC e Licenciatura Plena em Matemática pela Universidade de Uberaba - UNIUBE. Pós-graduada e Matemática pelas Faculdades Integradas de Jacarepaguá - FIJ, Pós-graduada em Gestão Escolar Integrada: Supervisão, Orientação e Inspeção Escolar pela Universidade Castelo Branco - UCB e Pós-graduada em Educação Profissional Integrada à Educação Básica na Modalidade EJA pelo Instituto Federal Educação, Ciências e Tecnologia do Espírito Santo - IFES. E-mail: wagnassouza@ @otmail.com.
} 
theorists of the area and summarizing their main ideas. Therefore, this study brings important contributions to educators who seek to improve their pedagogical practice more and mote

Keywords: University, teacher, Knowledge, Classroom.

\section{INTRODUÇÃO}

O presente estudo traz uma discussão que trata de analisar, à luz da didática, conhecimentos científicos adquiridos em cursos de graduação, mais especificadamente em bacharéis com base pedagógica insuficiente para que, futuramente, possam oportunizar conhecimentos a outras pessoas. O que se problematiza nesse estudo é o fato dos profissionais saírem dos bancos universitários com muito conhecimento em sua área específica e como demonstrar os mesmos a outras pessoas como professor se não possuem prática/didática exigida no contexto das salas de aula visto que saem das faculdades apenas com conhecimento teórico.

No mundo contemporâneo, profissionais de todas as áreas vêm atuando no campo educacional como docente o que muitas vezes é um desafio para esses profissionais. Apesar do conhecimento técnico em sua profissão, não tiveram nenhuma prática em lecionar ao longo da carreira e, muitas vezes, não possuem conhecimento didático suficiente.

Nesse sentido, ser um bom profissional na área de atuação, ter conhecimentos técnicos e experiências de trabalho seria uma vantagem para transmitir para outros estes saberes, mas torna-se uma incógnita essa transmissão sem conhecimento didático crítico/reflexivo.

Por outro lado, o trabalho vem mostrar que não seria suficiente apenas o conhecimento didático. Sendo assim, a pesquisa apresenta o perfil mais próximo do ideal do docente universitário contemporâneo. Mediante a tal prerrogativa, o objetivo desse artigo é apresentar as diversas facetas do docente universitário no mundo atual onde se encontra profissionais de diversas áreas atuando na prática do ensinar nos bancos universitários, em busca de entender os diferentes comprometimentos do docente universitário, desmistificando a ideia de que ter conhecimento prático e técnico em sua profissão seja suficiente para ser um bom professor. Espera-se que tal estudo seja um subsídio para novas pesquisas e que incentivem, não só aos novos docentes universitários a se aperfeiçoarem didaticamente, mas também aos experientes, tendo em vista que a construção do saber nunca se encerra. 
Em termos metodológicos, usou-se uma pesquisa bibliográfica, que segundo Cervo $(2005)^{2}$ “é uma modalidade de um dos tipos de pesquisa, procura explicar um problema a partir de referências teóricas publicadas em documentos". A principal vantagem desse tipo de pesquisa reside no fato de permitir ao investigador a cobertura de uma gama de fenômenos muito mais ampla do que aquela que poderia pesquisar diretamente.

A análise da revisão bibliográfica ocorreu no primeiro semestre de 2019, a partir das seguintes bases de dados: artigos científicos pesquisados no banco de dados SCIELO Brasil publicados no período de 2006 a 2016 em português. Os seguintes descritores serão utilizados nesta busca: professor universitário e docência universitária. Será realizada uma leitura minuciosa dos artigos a fim de não serem perdidos aspectos importantes para o enriquecimento do estudo e confecção da redação da pesquisa final. Através de leitura exploratória, para organizar as informações, será realizado fichamentos para então ser feita a análise dos dados.

Por conseguinte, o presente artigo mostrará que a função do docente universitário não podendo se limitar apenas ao oferecimento do ensino à docência universitária. Mais que ensinar os conhecimentos de uma ciência, deveria ter por missão ensinar a pensar uma determinada ciência e a pensar cientificamente seus conhecimentos pois o papel do docente universitário deve ser o de ajudar o aluno a pensar e a colocar esses conhecimentos em prática.

\section{DESENVOLVIMENTO}

Como a educação é um processo em eterna discussão o educador, ao ingressar como docente de nível superior, deve estar aberto a mudanças no modo de agir e ter presente a necessidade de democratizar o ensino, buscando se aperfeiçoar. Isso está bem ligado aos professores de ensino superior que possuem apenas formação em bacharel sem nenhum conhecimento didático. Mediante a isso, observa-se que mesmo com grande conhecimento do conteúdo precisa adequar-se didaticamente o seu modo de ensinar, pois a didática ainda continua sendo a melhor arma para criar e proporcionar estratégias de ensino.

\footnotetext{
2 Amado Luiz Cervo é um historiador brasileiro, autor de diversos livros, enfocando principalmente a política exterior do país. É Doutor em História pela Universidade de Estrasburgo. Possui graduação em História pela Universite de Strasbourg I (1966), mestrado em História pela Universite de Strasbourg I (1968) e doutorado em História pela Universidade de Strasbourg (1970).
} 
Para Comenius (2004, p.233) ${ }^{3}$ alguns pontos de referência são importantes no papel do professor (formação Bacharel) em sua prática pedagógica nos bancos universitários:

- A valorização do cotidiano do aluno;

- A construção de uma práxis educativa que estimula a sua consciência crítica tornando-se o sujeito de sua própria história;

- O diálogo amoroso entre professor e aluno;

- O professor como mediador entre o aluno e o conhecimento;

- O ensino dos conteúdos desvelando a realidade.

- A criatividade do professor em dar suas aulas,

- A necessidade da formação continuada de professores, como consequência dos desafios impostos pela área tecnológica, pois o aluno deve ser capaz de buscar informações em diferentes mídias e transformá-la em conhecimento.

Sendo assim, as ideias do autor acima afirma que o envolvimento dos professores universitários (um grupo unido e participativo é mais confiante diante dos seus saberes, dos seus desafios profissionais e não hesita diante das adversidades), visando à tomada de decisões e o desenvolvimento das lideranças no ensino, seja na elaboração do projeto educativo, seja na elaboração dos planos de curso, seja nos debates sobre temáticas de interesse para a coletividade do contexto universitário, apresenta confronto positivo de ideias, enriquece o trabalho tanto na prática como na pedagógica.

Posto isso, Vendramini $(2003)^{4}$ afirma que o educador de nível universitário é alguém que deve olhar seus alunos como pessoas com necessidades, dificuldades, fraquezas e pontos fortes, procurando, com esta postura, contribuir para seu crescimento nos diferentes aspectos.

Nesse sentido, Peres (2008) $)^{5}$ aponta que com as constantes mudanças no mundo globalizado, o educador que não possui uma didática em seus estudos, deve estar disposto a buscá-la, pois as mesmas surgem na educação, sendo essa um processo em eterna discussão. Cabe ao educador estar atento e propiciar novos métodos e técnicas que possam sanar os déficits deixados na mesma. Daí surge à necessidade de agir e democratizar o processo ensino/aprendizagem em busca de aprimoramento tanto profissional quanto pessoal, ou seja, o

\footnotetext{
${ }^{3}$ Jan Amos Komenský (em latim, Iohannes Amos Comenius; em português, João Amós Comênio; Nivnice, 28 de março de 1592 - Amesterdão, 15 de novembro de 1670) foi um bispo protestante da Igreja Morávia, educador, cientista e escritor checo. Como pedagogo, é considerado o fundador da didática moderna.

${ }^{4}$ Possui Graduação em Filosofia (Licenciatura Plena) pela Universidade Federal de Goiás (1993) e Mestrado em Filosofia pela Universidade Federal de Goiás (1997). Atua na área de Filosofia, com ênfase em Filosofia Antiga e Moderna, na área de Educação e em Metodologia de Pesquisa. Experiência Docente no Ensino Superior

${ }^{5}$ Possui graduação em Pedagogia Licenciatura Plena pela Faculdade de Ciências e Letras Plinio Augusto do Amaral(1986), graduação em Ciências Biológicas pela Pontifícia Universidade Católica de Campinas(1981), especialização em Especialização Em Ensino de Ciências no $1^{\circ}$ Grau pela Universidade Estadual de Campinas(1987), mestrado em Educação pela Universidade Estadual de Campinas(1993) e doutorado em Psicologia pela Pontifícia Universidade Católica de Campinas(2007).
} 
prático não pode estar desvinculado do didático.

Diante disso, Libâneo $(2000)^{6}$ menciona que é relevante destacar alguns pontos referenciais de suma importância no papel do professor universitário em sua prática pedagógica destacando o ensino de pressupostos teóricos a fim de que o discente seja capaz de se apoiar, através de análises crítico-construtivas em busca de um conhecimento. Através dos pressupostos teóricos o professor criará sua prática educativa didaticamente falando que estimulará no aluno a sua consciência crítica, tornando-se o sujeito de sua própria história. Através de suas análises o aluno poderá criticar e expor seus pontos de vista. O professor, nesse processo, deve ser o mediador entre o aluno, o pressuposto teórico de ensino e o conhecimento que ele adquirirá.

Nesse sentido Libâneo (2002) aponta que:

As contribuições da didática para os profissionais de educação constitui-se em eliminar a dicotomia que há entre a teoria e a prática. E para eliminar tal separação a didática se converte numa base teórico-prática que permite aos profissionais da educação sustentar uma compreensão mais substancial dos princípios, condições e meios de direção e organização do ensino pelos quais se asseguram a mediação docente de objetivos, conteúdos, métodos, em vista da efetivação da assimilação consciente de conhecimentos (LIBÂNEO, 2002, p. 144).

Para que esse processo seja de inteiro sucesso, o professor universitário deve valorizar o cotidiano, pois só através da valorização do ser humano que ele poderá contribuir para a formação de pessoas que focam o bem comum. Visando ajuda do professor em ministrar tais aulas surge a necessidade da formação dos mesmos para que o profissional possa enfrentar os desafios impostos pela área tecnológica, pois o aluno deve ser capaz de buscar informações em diferentes mídias e transformá-la em conhecimento.

Na visão de Cunha (2005) ${ }^{7}$ o objetivo fundamental do educador universitário é realizar a educação adequada às condições concretas da sociedade. Todo um esforço deve ser empreendido para que o espírito de cooperação possa permear a educação. A escola deve permitir ser atravessada pelo desejo de participação de toda a sociedade, empenhando-se na

\footnotetext{
${ }^{6}$ Libâneo é bastante conhecido no meio educacional brasileiro pelas profundas contribuições teóricas que produz na área.Suas reflexões sobre didática e prática de ensino e sobre sua perspectiva crítico-social dos conteúdos o colocam entre os mais importantes teóricos progressistas da educação.

${ }^{7}$ Mestre em Educação pela Universidade Católica de Brasília (2002).Especialização Latu Sensu em Psicopedagogia (1991), Psicologia Clínica - área de concentração: clinica Comportamental (1988) pela Universidade Católica de Goiás, Saúde Pública pela Faculdade de Ciências da Saúde de São Camilo (1987), Psicopedagogia Clínica para graduados pela Escuela Psicopedagogica de Buenos Aires - Argentina - (1994), graduada em Psicologia pela Universidade Católica de Goiás (1978).
} 
consciência de que a atividade educacional antes de ser simplesmente missão de saber é uma atividade social e política.

Com base nessa prerrogativa Comenius (2004), em suas pesquisas, aponta que a educação do século XXI enfoca a didática, pois fornece mapas de um mundo complexo e constantemente agitado e que ao mesmo tempo, é a bússola que permite navegar através dele. Desta maneira, ao se tratar da educação é indispensável referenciar que a vida é um longo e contínuo processo educativo, coextensivo e que amplia às dimensões da sociedade uma vez que o ser humano elabora seu pensamento, suas práticas profissionais pedagógicas mediante a compreensão de sua realidade.

Neste contexto, surge a necessidade permanente de desenvolvimento de capacidades e competências para os professores de formação em nível de bacharel para que os mesmos possam enfrentar as transformações diárias do mundo contemporâneo alterando-se a concepção tradicional da Educação. Não basta somente ensinar a ler e escrever, mas sim qualificar o processo educativo potencializado e adquirido pelos educadores: para a transformação do contexto educacional, colocando a didática como tema central e de grande importância nesse processo.

Nesse sentido a didática na educação superior surge a partir de uma proposta inovadora e comprometida com os sujeitos que a ela pertencer que deve em seu escopo ser permeada por ações educativas capazes de possibilitar o conhecimento entre educadores $\mathrm{x}$ educandos de forma leve, profunda, analítica e, principalmente, utilitária àqueles que recorrem ao ambiente escolar em busca do conhecimento não só apregoado pela instituição, mas também necessário a sua atuação profissional e, principalmente, pessoal.

Para isso, é necessário compreender os vários domínios do pensamento pedagógico dos conteúdos disciplinares específicos e respectivas metodologias para atuação éticoprofissional, implicando responsabilidade social para a construção de uma sociedade includente, justa e solidária.

A didática no ensino superior baseia-se então em pressupostos filosóficos e históricos, suas manifestações na prática pedagógica, dimensionamento dos conceitos de educação e instrução e das condições de desenvolvimento do indivíduo no seu contexto socioeconômico e político-cultural. A relação professor-aluno mediada pelos levantamentos das análises dos problemas de ensino e através de propostas de solução de problemas irão compreender o objeto de estudo da didática. Então, o papel da educação nesse estudo baseia-se em compreender o processo histórico de construção da psicopedagogia e sua contribuição para o 
ensino e aprendizagem centrada no desenvolvimento da competência técnica e política do educador e do educando no contexto do ensino superior.

Dentre as principais considerações desse estudo destacam-se:

Promover a reflexão crítica entre teoria e prática psicopedagógica considerando seu conteúdo e seu significado como algo produzido socialmente e historicamente.

Instrumentalizar o futuro educador para desenvolver as atividades de planejamento, execução e avaliação do processo ensino-aprendizagem;

Promover uma reflexão sobre as formas de comunicação, os aspectos afetivos emocionais e a dinâmica das manifestações do relacionamento professor-aluno no âmbito educacional.

Compreender os vários domínios do pensamento pedagógico e dos conteúdos disciplinares específicos e respectivas metodologias para atuação ético-profissional, implicando responsabilidade social para a construção de uma sociedade includente, justa e solidária.

Compreender o objeto de estudo da Didática, refletindo sobre a prática educativa e o processo de sistematização do conhecimento em sala de aula.

Estabelecer a relação entre Pratica Educativa, Educação e Instrução e seus influxos com a Didática e a Psicopedagogia;

Compreender o processo histórico de construção da Didática Psicopedagogica e sua contribuição para o ensino e aprendizagem centrada no desenvolvimento da competência técnica e política do educador;

Promover a reflexão crítica entre teoria e prática considerando seu conteúdo e seu significado como algo produzido socialmente e historicamente.

Instrumentalizar o futuro educador para desenvolver as atividades de planejamento, execução e avaliação do processo ensino-aprendizagem;

Refletir sobre as formas de comunicação, os aspectos afetivos emocionais e a dinâmica das manifestações do relacionamento professor-aluno no âmbito educacional.

Para Fazenda (2012, p.69) ${ }^{8}$ :

A didática tem como objeto de estudo o processo de aprendizagem na sua globalidade. Sendo assim, está inteiramente ligada à teoria da educação, às teorias da organização escolar, às teorias do conhecimento e à psicologia da educação. Esse suporte teórico é a base da prática educativa. Neste sentido, a didática torna-se o principal ramo de estudos da pedagogia, pois é necessário dominar bem todas as

\footnotetext{
8 . Possui graduação em Pedagogia pela Universidade de São Paulo (1963), Mestrado em Filosofia da Educaçao pela Pontifícia Universidade Católica de São Paulo (1978) Doutorado em Antropologia pela Universidade de São Paulo (1984) e Livre Docência em Didática pela UNESP (1991).
} 
teorias para que haja uma boa prática educativa. Assim, o educador dispõe de recursos teóricos para organizar e articular o processo de ensino e aprendizagem.

Nota-se que a problemática maior dos profissionais de Bacharel que ministram aulas em nível superior e que permeia a educação em torno da didática consiste na dificuldade de mediar conhecimento prático e teórico, na medida em que muitos educadores apresentam uma concepção fragmentada e ambígua desta interação chegando ao ponto de dissociá-las. Essa separação entre teoria e prática impossibilita os profissionais da educação de articular a teoria em proveito da prática, pois uma subsidia a outra. Como resultado dessa separação, a prática educativa tende a reduzir-se ao extremo do praticismo. Nesse sentido, a didática visa a contribuir para a superação dessa dificuldade, proporcionando ao profissional da educação embasamento teórico-prático.

Esse debate traz desdobramentos que afetam os papéis tradicionais das universidades no processo de formação de seus discentes e de produção de conhecimentos educacionais, bem como sua teoria, A prática de ensino, por ser uma teórico/prática, talvez a única com essa característica em se tratando na formação de pessoas, hoje, desenvolve-se a partir de vivências pedagógicas no interior da sala de aula nos bancos universitários teorizando-a. Em seu desenvolvimento o contato com o espaço educativo da sala de aula é imprescindível, pois é dessa realidade que as propostas de ensino devem emergir.

No entanto, é notável que a abordagem teórica é imprescindível na formação de um discente crítico, pois se constitui num dos elementos básicos para a análise qualitativa da realidade favorecendo a superação de uma concepção fundada no senso-comum, passando a uma consciência filosófico-científica da prática pedagógica

Fazenda (2012, p.69) também afirma:

$$
\begin{aligned}
& \text {...essa dimensão teórica precisa estar vinculada ao contexto educacional. A } \\
& \text { investigação da pratica educativa, a luz do referencial teórico, constitui-se, hoje, } \\
& \text { num importante elemento articulador de um projeto coletivo de formação do } \\
& \text { educador e produção de conhecimento em educação. }
\end{aligned}
$$

O professor universitário, em seu papel social, tem como responsabilidade planejar, organizar, dirigir, orientar e controlar o processo pedagógico. Isso significa, acima de tudo, criar situações de aprendizagem que vão desde o sensibilizar para o significativo, o importante, o novo, até chegar ao desafio, ao despertar o desejo pelo aprender. Para isso, não é suficiente se ater apenas aos aspectos temático-metodológicos do processo ensinoaprendizagem, mas também aos aspectos dinâmicos, dentre os quais estão aqueles que julgam o importante papel da comunicação e o sistema de inter-relações que se estabelece entre professores e alunos, alunos e alunos. 
De acordo com Coménius (2004, p.34):

... são hábeis para ensinar mesmo aqueles a quem a natureza não dotou de muita habilidade para ensinar, pois a missão de cada um é tanto tirar da própria mente o que deve ensinar, como sobretudo comunicar e infundir na juventude uma erudição já preparada e com instrumentos também já preparados, colocados nas suas mãos. Com efeito, assim como qualquer organismo executa qualquer sinfonia, olhando para a partitura a qual talvez ele não fosse capaz de compor nem executar de cor com a voz ou com o órgão, assim também por que é que não há o professor de ensinar na escola todas as coisas, se tudo aquilo que deverá ensinar e, bem assim, os modos como o há de ensinar o tem escrito como que em partituras?

Com base nas ideias apresentadas na citação acima, pode-se inferir que para se ensinar bem, o professor precisa ter tanto o conhecimento prático quanto o didático, pois os dois andam entrelaçados formando um só ritmo. Sendo assim, pode-se afirmar que tanto um como o outro são fundamentais para um professor de nível universitário.

\section{CONCLUSÃO}

Ao término desse estudo, percebe-se que os conhecimentos práticos e didáticos são fundamentais para um professor de nível universitário. Sendo assim, sua formação profissional para o magistério requer uma sólida formação teórico-prática.

Foi perceptível, ao longo do estudo, que o desempenho do educador precisa permear uma didática focada na prática. É preciso ser um profissional que reflita sobre sua prática e direciona oportunidades de ensino. Trata-se de entender que ensinar ultrapassa a sala de aula e proporciona um olhar holístico do mundo.

Nesse sentido, finaliza-se esse estudo mostrando que se um professor com formação em Bacharel almejar ser um bom professor no campo universitário também precisará de um domínio didático para atingir o principal objetivo da educação que é formar seres autônomos, capazes de interagir com o grande universo da sociedade de forma geral.

\section{REFERÊNCIA}

CERVO, Amado Luiz; BERVIAN, Pedro Alcino O conhecimento científico.2005.

COMENIUS, João Amos. Didática magna. São Paulo: Martins Fontes.2004.

CUNHA, Sueli de Paula. Psicopedagogia - O que é? In: Jornal da psicopedagogia, seção

Goiás. Ano. mar-abr, 2005.

FAZENDA, Ivani, C, A. Interdisciplinaridade: História, Teoria e Pesquisa. Campinas: Papirus.2012. 
LIBÂNEO, José Carlos. Pedagogia e pedagogos, para quê? São Paulo: Cortez, 2000.

Prática educativa, pedagogia e didática. In: Didática. São Paulo:

Cortez, 1994.-

PERES, Maria Regina. Psicopedagogia: aspectos históricos e desafios atuais. In: Revista de educação. PUC Campinas, V. 3, nº 5, p.41-45, nov. 2008.

VENDRAMINI, Luis Carlos, Guia para apresentação de trabalhos acadêmicos. Trindade: gráfica carvalho, 2013. 